\title{
Secagem solar de coentro: efeito de pré-tratamentos e do processo sobre, os aspectos físicos-químicos
}

\author{
Sun drying of coriander: effect of pretreatments and process on physical-chemical \\ aspects
}

\author{
Nathalia Horrana da Silveira ${ }^{1}$, Gerbson Vicente de Andrade Silva ${ }^{2}$, Franciely Kelly Pereira ${ }^{3}$, Adriano Sant'Ana ${ }^{4} *$
}

\begin{abstract}
RESUMO: Os objetivos deste trabalho foram estudar o processo de secagem solar do coentro, com e sem branqueamento, e avaliar os efeitos destes sobre as características físico-químicas do material desidratado. As amostras de coentro, foram submetidas ao branqueamento por imersão direta em água (BID) e branqueamento por imersão em saco (BIS). As amostras desidratadas, com e sem branqueamento, foram caracterizadas quanto à acidez total titulável e teor de ácido ascórbico. No tocante aos resultados referentes ao processo de secagem, constatou-se que não houve modificação significativa na velocidade de secagem das amostras com e sem branqueamento. Dentre os três modelos matemáticos utilizados para representar o comportamento das curvas de secagem, o modelo Midilli e Kucuk foi o melhor descreveu o comportamento das curvas, com $\mathrm{R}^{2}$ acima de $99 \%$ e menor desvio quadrático médio. Com relação ao produto desidratado, verificou-se que as amostras submetidas ao branqueamento BIS, apresentaram menor redução no teor de ácido ascórbico, cerca de 40\%, em relação à amostra original.
\end{abstract}

Palavras-chave: branqueamento, modelagem, desidratação

\begin{abstract}
The aim of this study were evaluate the sun drying process of coriander leaves, blanchied and unblanched, and assess the effect of pretreatments on physico-chemical aspects of dehydrated material. Coriander leaves were blanched by direct water imersion and blanched by imersion in polyethylene bag. Dehydrated samples, blanched and unblanched, were characterized by means total titratable acidity (TTA) and ascorbic acid content (AA). According to the results of drying process, it was not observed siginifcant changes in the drying rate of blanched and unblanched samples. Among the mathematical models applied to describe the drying process, Midilli and kucuk model, was the best model to describe the drying curves behavior, with $\mathrm{R}^{2}$ above $99 \%$ and the lowest mean square deviation. Blanched samples in polyethylene bag, showed TTA and AA values near the fresh samples.
\end{abstract}

Keywords: blanching, modelling, dehydration

\footnotetext{
*Autor para correspondência

Recebido para publicação em 10/10/2015; aprovado em 15/11/2015

${ }^{1}$ Graduando em Engenharia de Alimentos, Universidade Federal de Campina Grande, Pombal, Fone: 3431-4056, E-mail: nathaliehorrana@ hotmail.com

${ }^{2}$ Graduando em Engenharia de Alimentos, Universidade Federal de Campina Grande, Pombal, Fone: 3431-4056, E-mail: gerbsonandrade@ gmail.com

${ }^{3}$ Graduando em Engenharia de Alimentos, Universidade Federal de Campina Grande, Pombal, Fone: 3431-4056, E-mail: francielycruzeta@hotmail.com

${ }^{4}$ Professor Doutor, Universidade Federal de Campina Grande, Pombal, Fone: 3431-4056,E-mail: adriano_santana@yahoo.com.br
} 


\section{INTRODUÇÃO}

O uso da radiação solar para processamento de alimentos data de milhares anos atrás, onde grande parte dos alimentos, tais como grãos, frutas, hortaliças, carnes e peixes, eram deixados ao sol para desidratarem, prolongando assim o seu tempo de armazenamento ou melhorando suas características organolépticas.

A maior parte do território brasileiro está localizada relativamente próximo a linha do Equador (AGÊNCIA NACIONAL DE ENERGIA ELÉTRICA, 2005), o que garante poucas variações na duração incidência de raios solares durante o dia. Segundo os dados da ANEEL a variação da insolação ao longo do território nacional é bem ampla e variada, porém para o Alto Sertão paraibano a insolação pode ir de 8 até 10 horas, dependendo do período do ano.

Diante disso, o uso da radiação para a desidratação ou secagem de alimentos é bastante viável, tendo em vista o baixo custo em termos de equipamentos e energia e por ser uma tecnologia simples de implantar em comunidade rurais e cooperativas

A radiação solar foi empregada na desidratação de tomate por Latapi e Barret (2006), os quais avaliaram o emprego de pré-tratamentos sobre a qualidade do tomate desidratado, e por Amanlou et al. (2015), na secagem solar de coentro, milefólio e malva-rosa.

Dentre os mais variados produtos que podem ser desidratados por meio da secagem solar, o coentro (Coriandrum sativum) se destaca por ser uma olerícola condimentar de amplo uso e aceitação na Região Norte e Nordeste. O coentro é uma hortaliça condimentar, pertencente à família das umbelíferas e, apresenta-se como uma fonte de vários compostos nutricionais, como por exemplo, vitamina C, pró-vitaminas A, fibras, compostos antioxidantes, minerais, compostos terapêuticos, entre outros. Normalmente, esta hortaliça é consumida em seu estado natural, contudo, seu elevado teor de água favorece fortemente à processos bioquímicos de degradação, reduzindo assim seu tempo de prateleira.

Visando maximizar o tempo de prateleira deste produto várias são as técnicas que podem ser empregadas para prolongar a disponibilidade desta hortaliça, por exemplo, resfriamento, cocção, liofilização, secagem em camada fina, entre outros.

No tocante ao coentro, a secagem é uma operação unitária mais comumente empregada, diante do elevado teor de água desta cultura. Somado a isso tem-se uma expressiva a redução da quantidade de água, o que pode vir a garantir um maior tempo de prateleira, estabilidade bioquímica e microbiológica do produto desidratado. A introdução desta antiga técnica de conservação de alimentos, poderá representar ainda mais uma opção de renda para as comunidades rurais do Alto Sertão paraibano.
Visando minimizar os efeitos de degradação do processo de secagem sobre as características nutricionais e físicoquímicas do coentro e, também, acelerar o processo de secagem, o uso de pré-tratamentos é foco atual de diversas pesquisas. Dentre os tratamentos aplicados antes do processo de secagem, destaca-se o branqueamento, que é utilizado geralmente para a prevenção de sabores indesejáveis e mudanças na coloração dos produtos, resultante de reações enzimáticas.

O branqueamento já foi estudado como pré-tratamento à secagem em camada fina por Porntewabancha e Siriwongwilaicchat (2010), ao estudarem a cinética de secagem de alface, e por Silva et al. (2008), na secagem em camada fina de coentro.

Diante do exposto, o objetivo deste estudo foi analisar a cinética de secagem do coentro submetido a diferentes tipos de branqueamento em secador solar por exposição direta e avaliar os aspectos físico-químicos do produtos desidratado em relação ao produto em seu estado natural.

\section{MATERIAL E MÉTODOS}

\section{Local dos experimentos}

Os experimentos e as análises físico-químicas foram realizadas no Laboratório de Fenômenos de Transportes e Operações Unitárias (LOUFT) e Laboratório de Química, Bioquímica e Análise de Alimentos, respectivamente, do Centro de Ciências e Tecnologia Agroalimentar (CCTA), da Universidade Federal de Campina Grande (UFCG).

\section{Matéria prima}

Utilizou-se como matéria prima o coentro (Coriandrum sativum), variedade "verdão", proveniente do Mercado Municipal da cidade de Pombal-PB. O material ao ser adquirido foi encaminhado para o LOUFT, local este em que foi previamente selecionado, conforme sua maturação e frescor, sendo logo em seguida limpos e lavados com água corrente para a remoção de sujidades.

Posteriormente, o coentro foi sanitizado com uma solução de hipoclorito de sódio $(\mathrm{NaHC \ell O})$ à $15 \mathrm{ppm}$ por 10 minutos, sendo que após este tempo, o excesso de solução foi removido em água corrente.

Para os experimentos de secagem solar utilizou-se a parte aérea do coentro, a qual foi submetida aos seguintes prétratamentos antes da secagem: sem branqueamento (SB), branqueamento por imersão direta (BID) e branqueamento por imersão em saco de polietileno de alta densidade (BIS). Os branqueamentos foram executados em água a $95^{\circ} \mathrm{C}$ por 90 segundos, sendo que após este tempo as amostras foram rapidamente resfriadas em água fria $\left(10^{\circ} \mathrm{C}\right)$. Posteriormente, o excesso de água foi removido com auxílio de uma peneira.

\section{Secagem solar e modelagem}

A secagem solar foi conduzida em um protótipo de secador solar de exposição direta, confeccionado em madeira e área de exposição à radiação solar de $0,24 \mathrm{~m}^{2}$ (Figura 1). 
Figura 1. secador solar de exposição direta com coletor solar.

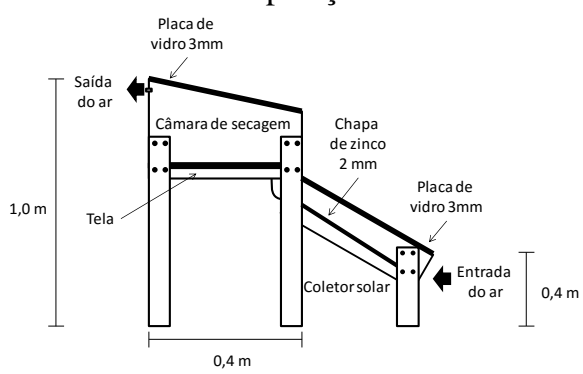

Para a secagem das amostras, com e sem branqueamento, o secador foi exposto à radiação solar por cerca de 30 minutos para um aquecimento prévio. As amostras de coentro (cesto + amostra), logo em seguida foram introduzidas no interior do equipamento para início dos experimentos.

A secagem solar, foi conduzida em triplicata em dias distintos de alta insolação e o posicionamento dos cestos no interior do equipamento foi de forma aleatória. $\mathrm{O}$ equipamento foi exposto a radiação solar por volta das 6 horas da manhã e o processo de secagem iniciou-se por volta das 6:30 horas, finalizando as 17:00 horas.

Periodicamente, os cestos contendo as amostras foram retirados para verificação da perda de água, por meio de pesagens a cada uma hora, em balança semi-analítica Bioprecisa Modelo BS3000A $\pm 0,01 \mathrm{~g}$.

Ao término do processo de secagem, quando não mais foi observado variação na perda de massa nas amostras os experimentos foram encerrados, sendo as amostras encaminhadas para determinação do teor de água conforme metodologia descrita em Instituto Adolfo Lutz (2008).

Com o registro de perda de água, bem como o teor de água final do produto, foi possível determinar a razão do teor de água (RTA), (Eq. 1), o qual foi utilizado para a construção das curvas de secagem e aplicação de modelos matemáticos.

$$
R T A=\frac{\left(T A_{t}-T A_{e}\right)}{T A_{0}-T A U_{e}}
$$

Em que TAt, TAe e $\mathrm{TA}_{0}$ são, respectivamente, o teor de água em função do tempo, teor de água no equilíbrio e teor de água inicial do produto, todos expressos em base seca (\%b.s.)

Às curvas de secagem obtidas foram aplicados modelos matemáticos de Midilli e Kucuk (Eq. 2), Page, (Eq. 3), Aproximação da difusão (Eq. 4) e Logarítmico (Eq. 5) (SILVA, 2006), visando identificar qual deste pode ser utilizado na descrição do comportamento das curvas de secagem solar do coentro.

$R T A=a * \exp \left(-k * t^{n}\right)+b * t$

Eq. 2

$R T A=\exp \left(-k * t^{n}\right)$

$R T A=a * \exp (-k * t)+(1-a) * \exp (-k * b * t)$

Eq. 3

$R T A=a * \exp (-k * t)+c$

Eq. 4

Eq. 5

Em que $\mathrm{t}$ é o tempo de secagem em horas, $\mathrm{k}$ é constante de secagem $\left(\mathrm{h}^{-1}\right)$, e $n, b, c$ e $a$ são parâmetros dos modelos.

Visando identificar qual modelo melhor descreve o comportamento das curvas de secagem utilizou-se como critério de seleção do coeficiente de determinação $\left(\mathrm{R}^{2}\right)$, o desvio médio relativo (DQM) (Eq. 5) e o gráfico Valores normais esperados em função dos resíduos (SILVA, 2006).

$D Q M=\sqrt{\frac{\sum\left(R U_{p r e}-R U_{\exp }\right)^{2}}{N}}$

Eq. 5

Em que $R U_{\text {pre }}$ é a razão do teor de água predita pela equação, $R U_{\text {exp }}$ é a razão do teor de água experimental e $N$ é o número de observações realizadas durante o experimento.

\section{Caracterização físico-química}

Visando avaliar os efeitos do processo de secagem, bem como dos branqueamentos sob as características físicoquímicas do coentro desidratado, foram conduzidas as análise de acidez total titulável e teor de ácido ascórbico A acidez total titulável e o teor de ácido ascórbico foram quantificados conforme metodologia descrita no Instituto Adolfo Lutz (2008).

\section{Delineamento estatístico dos experimentos}

Os resultados referentes às caracterizações físicoquímicas do coentro foram submetidos à análise de variância (ANOVA) para a avaliação da significância estatística dos experimentos. Havendo a significância estatísticas, as médias obtidas foram submetidas à comparação de médias pelo teste de Tukey, a nível de 5\% de probabilidade. Para a ANOVA e comparação de médias utilizou-se o programa ASSISTAT, versão 7.2 beta (SILVA; AZEVEDO, 2002).

\section{RESULTADOS E DISCUSSÃO}

Na Figura 2, a representação das curvas de secagem do coentro sem branqueamento (SB), branqueado por imersão direta (BID) e branqueado por imersão em saco (BIS) de PEAD encontram-se apresentados. Observou-se, inicialmente, duas fases distintas de secagem, sendo a primeira fase, mais rápida, a taxa constante de secagem, indicando que o processo de migração de água da amostra para o meio externo, ocorre unicamente pela evaporação de fino filme de água na superfície da amostra.

A segunda fase, a taxa decrescente, ocorre após 5 horas de secagem, indicando que o processo migratório de água das amostras para o meio externo ocorre, principalmente, por processo de difusão. Estas observações encontram suporte nos estudos conduzidos por Amanlou et al. (2015), os estudaram a secagem solar de coentro, milefólio e malva rosa.

Figura 2. Curvas de secagem do coentro com e sem branqueamento.

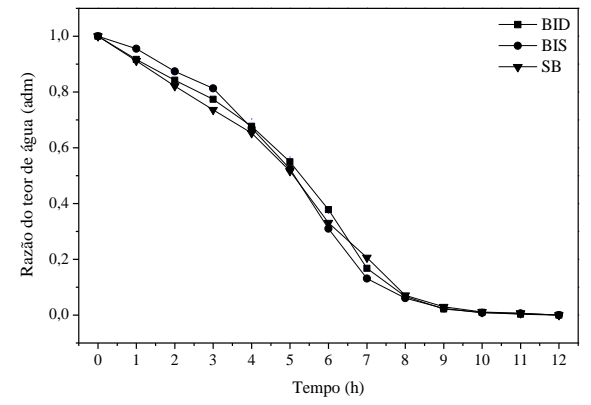


Com relação aos pré-tratamentos utilizados, verificou-se que estes não alteraram significativamente $o$ processo cinético de secagem, entretanto, foi constatado que o coentro sem branqueamento apresentou-se ligeiramente mais rápido, o que pode ser observado pelo maior valor na constante de secagem (k) na Tabela 1.

$\mathrm{O}$ coentro em seu estado natural apresentou teor de água inicial de cerca de $90 \%$ (b.u.), e o tempo para que as amostras desidratadas, com e sem branqueamento, apresentassem teor de água final médio de $6,8 \%$ (b.u.), foi de 10 horas.

A Resolução de Diretoria Colegiada N ${ }^{\circ} 272$ de 2005 da Agência Nacional de Vigilância Sanitária (2015) determina que os produtos vegetais secos ou desidratados, o teor de água ser no máximo até $12 \%$ (b.u.). Sendo assim, os resultados referentes ao teor de água das amostras desidratadas, com e sem branqueamento, encontram-se dentro da faixa de valores estabelecidos pela legislação brasileira.

Os tempos médios, requeridos para reduzir o teor de água de $90 \%$ b.u. das amostras, com e sem branqueamento, até o teor de água médio de $6,78 \%$ b.u. nas mesmas condições de temperatura foi de 10 horas.
Em estudos de secagem solar conduzidos com salsa, Akpinar e colaboradores (2006), em 6 horas de processo, reduziram o teor de água da salsa de $90 \%$ até $10 \%$ (b.u.) em cerca de 6,5 horas, tendo uma área de secagem por exposição direta de $0,16 \times 0,25 \mathrm{~m}^{2}$. Tal observação indica teor de água semelhante pode ser alcançado pelo protótipo desenvolvido em tempo abaixo de 10 horas.

$\mathrm{Na}$ Tabela 1 encontram-se os parâmetros dos modelos aplicados aos dados experimentais obtidos na secagem solar do coentro, com e sem branqueamento. A análise destes resultados indicou que o modelo de Midilli e Kucuk foi o modelo que prediz, com precisão, o comportamento dos resultados de secagem, por apresentar maior coeficiente de determinação $\left(\mathrm{R}^{2}\right)$, entre 99,31-99,71 e menor desvio quadrático médio (DQM), com valores entre 0,00048 e 0,00126 .

Os valores médios referentes a acidez total titulável (ATT) e o teor de ácido ascórbico (AA), expressos em base seca, do coentro em seu estado natural (IN), desidratado sem branqueamento (SB), com branqueamento por imersão direta (BID) e branqueamento por imersão em saco (BIS), encontram-se apresentados na Figura 3.

Tabela 1 - Parâmetros dos modelos utilizados na descrição do comportamento dos dados de secagem solar do coentro, com e sem branqueamento.

\begin{tabular}{|c|c|c|c|c|c|c|c|c|}
\hline \multirow{2}{*}{ Amostras } & \multirow{2}{*}{ Modelos } & \multicolumn{4}{|c|}{ Parâmetros } & \multirow[b]{2}{*}{$\mathrm{c}$} & \multirow{2}{*}{$\mathbf{R}^{2}(\%)$} & \multirow{2}{*}{ DQM } \\
\hline & & $\mathrm{a}$ & $\mathrm{k}\left(\mathrm{h}^{-1}\right)$ & $\mathrm{n}$ & $\mathrm{b}$ & & & \\
\hline BID & \multirow{3}{*}{$\mathrm{N}$} & 0,933 & 0,0061 & 2,830 & $-0,0011$ & - & 99,310 & 0,00126 \\
\hline BIS & & 0,960 & 0,0062 & 2,906 & $-0,0002$ & - & 99,713 & 0,00081 \\
\hline SB & & 0,941 & 0,0139 & 2,395 & $-0,0017$ & - & 99,338 & 0,00048 \\
\hline BID & \multirow{3}{*}{ Page } & & 0,0145 & 2,413 & - & - & 98,742 & 0,04215 \\
\hline BIS & & & 0,0103 & 2,651 & - & - & 99,538 & 0,02637 \\
\hline SB & & & 0,0249 & 2,138 & - & - & 98,864 & 0,03903 \\
\hline BID & \multirow{3}{*}{$\begin{array}{c}\text { Aproximação da } \\
\text { difusão }\end{array}$} & $-630,6$ & 0,4377 & - & 0,9979 & - & 95,818 & 0,07904 \\
\hline BIS & & $-580,0$ & 0,4680 & - & 0,9975 & - & 96,629 & 0,76426 \\
\hline SB & & $-655,5$ & 0,4358 & - & 0,9981 & - & 96,801 & 0,68919 \\
\hline BID & \multirow{3}{*}{ Logarítmico } & 2,201 & 0,0640 & - & - & $-1,126$ & 95,664 & 3,95307 \\
\hline BIS & & 1,990 & 0,0786 & - & - & $-0,882$ & 94,975 & 4,03308 \\
\hline SB & & 1,950 & 0,0750 & - & - & $-0,885$ & 96,784 & 1,15306 \\
\hline
\end{tabular}

Figura 3. Acidez total titulável e ácido ascórbico das amostras de coentro em estado natural e desidratadas com e sem branqueamento.

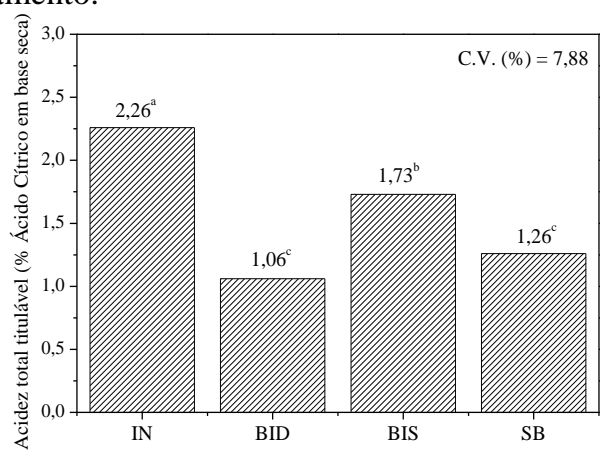

Conforme análise destes resultados, observou-se redução na acidez total titulável (ATT), de 53,3\%, 23,8\% e $44,5 \%$, para as amostras BID, BIS e SB, respectivamente. Entretanto, as amostras BID e SB não diferiram do ponto de vista estatístico. A redução mais acentuada na ATT, para as amostras BID, é atribuída em grande parte ao processo de lixiviação dos ácidos orgânicos presentes nas amostras.

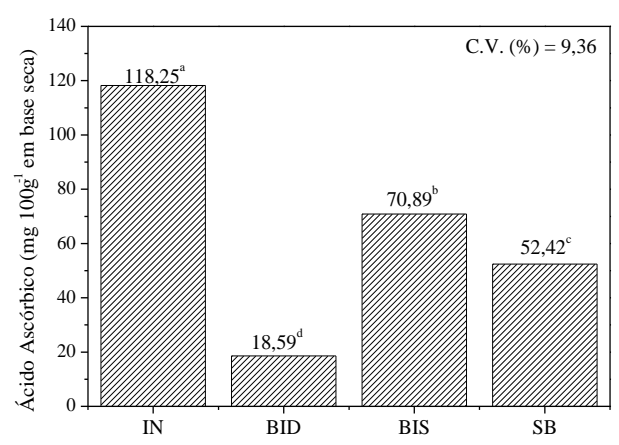

Por outro lado, para as amostras BIS houve menor redução na ATT, cerca de $23,8 \%$, sendo justificado pela proteção exercida pelo saco de polietileno de alta densidade (PEAD), o qual minimizou as perdas por lixiviação para o meio aquoso.

Com relação ao ácido ascórbico conforme análise destes resultados verificou-se que o resultado de AA para a 


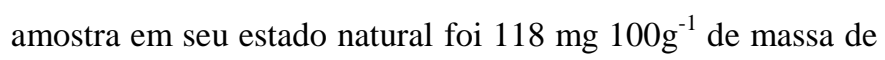
seca, sendo compatível com o obtido por SILVA (2006), cerca de $93,8 \mathrm{mg} 100 \mathrm{~g}^{-1}$ de massa seca, o qual estudou o processo de secagem do coentro em secador de leito fixo nas temperaturas entre 40 e $80^{\circ} \mathrm{C}$.

Os resultados referentes a AA também encontram-se próximos aos observados por Khanum, Sulochanamma e Borse (2013), cerca de $120,5 \mathrm{mg} 100 \mathrm{~g}^{-1}$ de massa seca. No estudo os autores estudaram a secagem do coentro em estufa com circulação de ar $\left(60\right.$ a $\left.100^{\circ} \mathrm{C}\right)$, em secador solar e secador por irradiação de infravermelho.

Com relação aos efeitos do processo de secagem e do branqueamento, verificou-se as reduções de $84,3 \%, 40,0 \%$ e $55,7 \%$, para as amostras BID, BIS e SB, respectivamente. Esta constatação sugere que a presença do saco de PEAD no BIS promove uma proteção a mais no AA no processo de secagem solar do coentro por exposição direta.

\section{CONCLUSÃO}

Diante dos resultados obtidos, pode-se concluir que a utilização da secagem solar permite a obtenção de um produto desidrato com teor de água em conformidade com a legislação. O uso do branqueamento como pré-tratamento para o processo de secagem, não modificou a velocidade de secagem e ocasionou perdas significativas no teor de ácido ascórbico do coentro. O modelo de Midili foi o modelo matemático que melhor representou o comportamento das curvas de secagem das folhas de coentro, sendo preditivo ao processo.

\section{REFERÊNCIAS BIBLIOGRÁFICAS}

AGÊNCIA NACIONAL DE ENERGIA ELÉTRICA. Atlas de energia elétrica do Brasil. $2^{a}$ ed. Brasília: ANEEL, 2005. 243 p.

AGÊNCIA NACIONAL DE VIGILÂNCIA SANITÁRIA. Resolução de Diretoria Colegiada $N^{\circ} 272$ de 22 de setembro de 2005 - Regulamento técnico para produtos vegetais, produtos de frutas e cogumelos comestíveis. Disponível em:< http://portal.anvisa.gov.br/wps/wcm/connect/ac0938004 7457ea18a84de3fbc4c6735/RDC_272_2005.pdf?MOD= AJPERES>. Acesso em: 17 de dezembro de 2015.

AKPINAR, E. K.; BICER, Y.; CETINKAYA, F. Modelling of thin layer drying of parslaey leaves in a convective dryer and under open sun. Journal of Food Engineering, v. 75, n. 3, p. 308-315, 2006.

AMANLOU, Y.; HASHJIN, T.; GHOBADIAN, B.; NAJAFI, $\mathrm{G}$. Mathematical modelling of thin-layer solar drying for yarrow, coriander and hollyhock. International Journal of Food Engineering, v. 11, n. 5, p. 691-700, 2015.

INSTITUTO ADOLFO LUTZ. Normas Analíticas; métodos químicos e físicos para a análise de alimentos. 4 ed. São Paulo, Instituto Adolfo Lutz,2008.

KHANUM, H.; SULOCHANAMMA, G.; BORSE, B. B. Impact of drying coriander herb on antioxidant activity and mineral content. Journal of Biological \& Scientific
Opinion, v. 1, n. 2, 2013, p. 50-55.

LATAPI, G.; BARRETT, D. M. Influence of pre-drying treatments on quality and safety of sun-dried tomatoes. Part. I: Use of steam blanching, boiling brine blanching, and dips in salts or sodium metabisulfite. Journal of Food Science, v. 71, n. 1, p. 24-31, 2006.

PORNTEWABANCHA, D.; SIRIWONGWILAICHAT, P. Effect of pre-treatments on drying characteristics and colour of dried lettuce leaves. Asian Journal of Food and Agro-Industry, v. 3, n. 06, p. 580-586, 2010.

SILVA, A. S.; ALMEIDA, F. de A. C.; LIMA, E. E.; SILVA, F. L. H.; GOMES, J. P. Drying kinetics of coriander (Coriadrum sativum) leaf and stem. Ciencia y Tecnologia Alimentaria, v. 6, n. 1, p. 13-19, 2008.

SILVA, A.S. Mini Processamento e secagem de folha e caule do coentro (Coriandurum sativun) var. verdão para a produção de extrato seco. Dissertação de mestrado em engenharia agrícola, Campina Grande, PB. UFCG, 2006.

SILVA, F.A.S. A; AZEVEDO, C.A.V.. Versão do programa computacional Assistat para o sistema operacional Windows. Revista Brasileira de Produtos Agroindustriais, v.4, n.1, p.71-78, 2002. 